\title{
Developing a fall prevention program: What are the views and opinions of people with multiple sclerosis?
}

\author{
Firat Kesgin ${ }^{a *}$, Kitty Suddick ${ }^{\mathrm{a}}$, Christoph Heesen ${ }^{\mathrm{b}}$ and Jonathan J. Wright ${ }^{\mathrm{a}}$ \\ a School of Health Professions, University of Brighton, Eastbourne, East Sussex, UK; ${ }^{b}$ \\ MS Day Hospital and Institute of Neuroimmunology and Multiple Sclerosis, University \\ Medical Center Hamburg Eppendorf, Hamburg, Germany
}

*Firat Kesgin, Brandstwiete 58, 20457 Hamburg, Germany, email:

firat.kesgin@gmail.com 


\title{
Developing a fall prevention program: What are the views and opinions of people with multiple sclerosis?
}

\begin{abstract}
Purpose: Falls are common in people with multiple sclerosis, yet there are a few targeted fall prevention programs. Existing programs report a high dropout rate and a low adherence, which may be due to a mismatch between program characteristics and participants preferences. To clarify a possible discrepancy, this study investigates the views and opinions of persons with multiple sclerosis on fall prevention programs. Methods: Two focus groups $(n=11)$ were conducted with people with multiple sclerosis who have a history of falls, near falls or who are concerned about their balance/ falling risk. The data was analysed using a qualitative content analysis with an inductive approach. Results: Participants preferred short-term programs taking place in rehabilitation clinics, or physiotherapy or occupational therapy practices. They believed that the awareness for fall prevention needs to be raised among healthcare professionals. Participants expected better consultation from physio and occupational therapists regarding mobility aids and home modification. The participants wanted the programs to be practical, in-person and in groups. Online interventions were strongly rejected. Further, participants wanted balance/ strength exercises and the inclusion of falling techniques in programs. The competence of knowing and accepting capacity may be an important factor in preventing falls. Conclusions: Investigating the views and opinions of persons with multiple sclerosis on fall prevention programs gave important information which can be used to inform the development of such programs.
\end{abstract}

Keywords: multiple sclerosis, accidental falls, accident prevention, physical therapy modalities, focus groups, qualitative research

\section{Introduction}

Sensory, motor, visual and balance impairments are the most common presenting symptoms in people living with multiple sclerosis (MS) [1]. Balance impairments are especially associated with an increase in fall risk [2]. A meta-analysis of four studies that prospectively collected data from 537 participants over 3 months, reported that $56 \%$ of participants had fallen once and $37 \%$ were frequent fallers (twice or more) [3]. There 
is also evidence for the prevalence of fear of falling and associated activity curtailment in people with MS who are considered as fallers as well as non-fallers [4,5]. It was also reported that fear of falling is associated with a higher risk of future recurrent falls [6]. Thus, it can be hypothesized that falls and fear of falling trigger a vicious cycle which lead to reduced physical activity, further deconditioning and more falls. Consequently, it seems essential to develop interventions that reduce falls and fear of falling to prevent activity curtailment and its negative consequences for people with MS.

The limited awareness, lack of guidelines and implementation of fall prevention programs in Germany, are of specific relevance to this study [7]. In general, it must be mentioned that worldwide the number of investigations focusing on fall prevention in people with MS is low and this area is even considered to be in its infancy [5].

Consequently, there are still a lot of questions that need to be answered by research.

Evidence-based practice is considered to be a three-legged stool that tries to reconcile the perspective of research, clinicians and patients in clinical practice [8]. To our knowledge, there have been no previous qualitative studies that have tried to investigate the patients' perspectives regarding fall prevention interventions. We believe that at this early stage of exploration, qualitative data from people with MS can make a positive contribution to our knowledge and understanding of fall prevention programs as practiced at this time.

Reported fall prevention program adherence rates of $45 \%$ are another reason to emphasize the patients' perspectives [9]. Adherence seemed to decrease over time with longer-duration programs [9]. High dropout rates due to lack of time, illness and the high strain of traveling and participating were also reported [10]. It could be hypothesized that a program that is developed in collaboration with people with MS and not just for people with MS - could raise adherence and reduce dropout rates, 
which, in turn, could increase effectiveness of interventions. In this sense, the patient leg of the three-legged stool of evidence-based practice needs to be emphasized and thus, our study aims to clarify the participants' perspectives, views and opinions on fall prevention programs.

\section{Methods}

\section{Research design}

As the aim of this research was to systematically generate theory from the data, a qualitative content analysis with an inductive approach was conducted by using the sentences of focus group transcripts as the unit of analysis. Focus groups are commonly used and recommended to design intervention programs [11].

\section{Recruitment}

All participants were recruited via an advertisement of the study on the German MS society's website and via emails from the German MS Society to regional groups. Interested participants approached the first author by phone and asked for more information. A detailed information sheet was sent to those by email and interested participants returned a signed consent form. Participation was voluntarily, and participants could withdraw at any time.

A sample size of six to ten people is postulated for focus groups [12], but it was reported that previous focus groups with people with MS used smaller sample sizes due to attrition or low uptake as a result of disability or difficulties attending sessions [13]. Thus, it was determined to recruit twelve participants for two focus groups. Finally, eleven people showed interest, and all were recruited for the study. All interested people took part, and no one dropped out. The inclusion criteria for the study was: 
- Diagnosis of MS made by a physician

- Minimal age limit of 18 years

- people with MS who have a history of falls, near falls or who are concerned about their balance or falling risk

\section{Data collection}

Both focus groups took place in the evening at the library of the MS day-care clinic of the University Medical Centre Hamburg on two consecutive days. The participants, the first author and an assistant were the only people in this room. The first author is a physiotherapist with expertise in vestibular rehabilitation and fall prevention. The assistant took notes, but was not involved in the dialogue. The participants were not known to the researchers prior to the study.

A discussion schedule was developed to semi-structure the focus groups (Supplementary Material 1). The discussion schedule was pilot tested with three physiotherapist colleagues by the first author. The age, gender, type of MS, time since diagnosis, history of falls or near falls and experience with fall prevention programs were gathered (Table 1, Table 2 and Table 3 ) at the beginning of the focus group for both demographic purposes, as well as to introduce each other, and to start the conversation. Both focus groups took 90 minutes and were audio recorded and transcribed verbatim. The transcripts were then translated from German to English by the first author and data was pseudonymized for analysis.

[Table 1 near here]

[Table 2 near here]

\section{Data analysis}

The principles of qualitative content analysis were used as a guide. The first author 
strictly followed the steps of qualitative content analysis by absorbing data, developing unique codes, conducting preliminary coding, coding content, then identifying categories across codes, identifying themes across categories and drawing interpretations and implications [14].

During preliminary coding the second author was involved in the coding process and several pages of both transcripts were coded by two authors (FK \& KS). Including the preliminary coding, the transcripts were re-coded four times over a period of six weeks. The first author did not review previous coding between the four codings. This was done for consistency reasons [14]. All congruities and discrepancies were noted in a reflexive journal. New codes were added, or existing codes were modified to resolve discrepancies. The fourth and last coding did not result in any discrepancies and the coding process was deemed completed.

The second phase of qualitative content analysis, namely categorization and interpretations, was repeated three times before completion. The first author created concept maps for categorization. One to two weeks passed between the categorizations and previous maps were not viewed before new concept maps were created. After each categorization, results were discussed with the second author. The feedback was noted in the reflexive journal and the categorization was modified until both authors agreed on all themes and patterns across categories.

The first author collected and constantly reviewed the reflexive journal during all phases of data generation and analysis to improve the trustworthiness, to add credibility and to monitor the development from preliminary theories to final conclusions.

\section{Ethical approval}

The study received ethical approval from the University of Brighton's ethics committee. 
As the study was executed in Germany, the approval of the Hamburg Chamber of Physician's ethics committee was also needed and gained.

\section{Results}

Two focus groups were conducted with a total of 11 participants. The sample was predominately female $(n=8)$ and had a mean age of 51 . The demographic details are presented in Table 1 and Table 2 . The first focus group predominately consisted of newly diagnosed people and the second focus group consisted of people with a longer disease duration (Table 3).

[Table 3 near here]

The findings were divided into two categories: (1) Views and opinions of people with MS regarding the organization of a fall prevention program and (2) views and opinions of people with MS regarding the content of a fall prevention program (Figure 1).

[Figure 1 near here]

\section{(1) Views and opinions of people with MS regarding the organization of a fall prevention program}

\section{Time-related factors}

Participants from both focus groups agreed that shorter-duration programs would be preferred. Programs that consist of 5 weeks with 5 weekly 90 -minute sessions were recommended specifically by the first focus group.

Mary: "I would consider carefully before I sign up for a 10-week program because I don't know if I could attend 10 weekly, consecutive meetings. [...]. I would prefer 5 to 6 weeks, because I believe that I could engage in that." 


\section{Location of program}

Physiotherapy or occupational therapy practices, sport clubs and fitness centres were mentioned as desired locations. Participants preferred these locations for follow-up appointments in particular. Rehabilitation clinics were also mentioned, as people are onsite and can concentrate on their rehabilitation, which makes it very easy to participate.

Accessibility, especially the accessibility by public transportation, was emphasized by the participants. They agreed that this would affect the turnout rate of the program immensely.

Ruby: "I find it important that it is decentralized. That you don't have to use bus or train for 90 minutes to attend the program."

\section{Organization, financing and funding}

Participants wanted the programs to be organized and funded by clinics, statutory health insurers and the German MS Society. The statutory health insurers were criticized because although they pay for the consequences of falls and spend large sums of money on medication, they don't fund fall prevention programs.

Mary: "I wish that such programs would be financed by healthcare insurances, because otherwise we need to pay the consequences of the falls."

Interestingly participants suggested that they would support financing by paying a participation fee. They believed that patient motivation is higher, if they pay for a service.

Sarah: "If you have participation fees, you consider carefully 'should I participate or not?'." 
Another suggestion was that the statutory health insurance reimburses all costs, if participants took part in all meetings. It was believed that this would increase turnout rate, too.

During the discussion of financing and funding, the issue of healthcare facilities needing to increase their awareness of fall prevention was raised. Participants explained that they received little support and guidance from healthcare professionals. Participants in both groups spoke of a neglect of the topic and complained that they were not advised how to prevent themselves from falling in consultations.

Patricia: "Not even in rehabilitation centers, has someone ever mentioned fall prevention. I know they do it, they train balance... but I can't think of, that someone ever mentioned this term."

Mary: "It was never discussed explicitly with me either. The physiotherapist [...], he addressed all my requests. I needed balance exercises, then he did it. But it didn't originate with him. [...]"

General practitioners and neurologists see falls as a symptom of MS and it appears that falls are "normal" in MS and are just to be accepted.

Clara: "The reaction to 'I fell' sounded like 'well what do you expect, you have MS'. 'Oh ok, thank you!' Everybody expects us to fall." Mary: "Falling is just a symptom of MS. It belongs to it."

Participants agreed that falls must be discussed, addressed and included in medical check-up questionnaires.

"Mary: It would be very important, that it be included in a check-up, just as they ask if you have visual disturbances, or bladder problems, the same way you could address this topic." 


\section{Potential Instructors}

Physiotherapists, occupational therapists, judo trainers and psychologist were mentioned as possible instructors. Participants also like two disciplines leading together. Participants were disinclined to accept laymen as instructors for two reasons:

(1) The instructor needs to be an expert and be competent. They can modify exercises for more impaired people and can better understand the influence of comorbidities.

Kate: "In my exercise group we have people that are not able to do the drill and then they get alternative drills."

Clara: “And if you have a participant with another diagnosis, let's say MS and 'blabla' or with another symptom the person won't know, so we need competence!"

(2) Assuming each fall prevention group would need one instructor, using people with MS would require at least two people as cover in case their symptoms hindered their attendance. The second group especially emphasized that people with MS would be unreliable program leaders.

Laymen were acceptable as instructors for those who want to continue the program after the intervention (follow-up).

During this discussion, the participants also explained that they expect more expertise from physiotherapists and occupational therapists. A problem with inadequate consultation concerning mobility aids and home environment modifications were mentioned in the focus groups. 


\begin{abstract}
"Ruby: Mobility aids can give you security, but if they don't fit, they can also make pain and disturb you more. It would be good, if the supply of aids improves, there is room for improvement."
\end{abstract}

Theory vs. practice

The first focus group would prefer an appreciably higher practical content. The reason was that falling is a practical subject which requires physical training. This group found physical strategies to prevent falls to be more important than non-physical interventions. Practicing how to fall safely or how to use mobility aids, especially requires practical guidance.

Yet, this group agreed that each meeting could have a thematic emphasis and that short impulse talks could initiate the practice sessions. This group emphasized that the theory must be fun and interactive. Dry, long talks were rejected.

The second group supported a 50-50-distribution of theory and practice. It was discussed that relevant topics (such as visual impairments and falling) would have added value.

Group vs. 1-on-1 therapy

All participants agreed that the program should be executed with a group, because:

- Peers give each other tips; exchanging and sharing information was mentioned many times.

- Peers learn from each other how to cope with the exercises.

- It is motivating - Ruby: "It disciplines me, motivates me to get up from the couch."

Some participants recommended that 1-to-1 therapy (e.g. physiotherapy) could be done additionally or as follow-up, but not as the main program. 
Online vs. personal

All of the participants were strictly against online interventions. Their arguments were:

- An instructor that can help physically is necessary in order to practice falling and getting up. In general, with an online program there would be no correction, tips and guidance from an instructor.

Clara: "I want to be on the mat. I want someone to tell me "fall like this, hold on like this'. That doesn't work online. We don't just want talks, we want to work practically."

- There would be no interaction with peers, no group energy.

- Participants won't exercise by themselves, as they could fall and get injured at home; at home they lack the exercise equipment.

- People would make excuses (e.g. too tired, too boring) and adherence to the program would be low.

Ruby: "At home, I keep postponing everything and at the end of the year I look back and think 'you made it 3 times'."

As mentioned before, participants rejected a high proportion of theory. Online interventions were deemed appropriate for theory (e.g. talks) but not for practice. Online interventions were only found acceptable for follow-up or under unusual circumstances (Kate: "If you can't access the gym or if you are depressed").

\section{Mixed groups vs. MS groups}

The first group preferred an MS group. Some participants wanted specific MS groups, as they could connect better with equally affected people. 
Mary: “[...] what's so special about MS, is that it hits us out of the blue, suddenly our legs give away, you don't expect it. [...], because you don't experience these sudden falls otherwise. The patient with hemiplegia also falls, but differently."

One participant experienced both - a mixed neurological group and MS group in a rehabilitation clinic. She found the MS group better and more effective than the mixed group.

The second group preferred a mixed group for two reasons:

(1) One participant emphasized that mixed groups would give them the chance to work with other people that have other problems.

(2) Mixed groups would prevent a self-help group atmosphere with negative effects (“pitying themselves instead of practicing").

\section{(2) Views and opinions of people with MS regarding the content of a fall prevention program}

\section{Interventions to decrease falls-associated impairments}

The participants named several impairments that caused their falls (Table 4). Participants in both groups believed that those impairments need to be improved to prevent falls. Improving balance and leg strength was repeatedly mentioned.

[Table 4 near here]

\section{Interventions to improve attentiveness}

Participants mentioned repeatedly how important it is to be careful and to pay attention and concentrate during activities. They must regulate their pace and look ahead, recognize fall or trip hazards and plan their activities. They emphasized that these strategies are important during risky activities and environments (Table 4). The 
opinions about whether awareness and attentiveness should be practiced differed among participants.

Sarah: "I am lucky, I always know in advance, that I will fall. Therefore, I have the chance to catch myself. [...] I always somehow managed to stop it. But maybe this kind of things should be practiced."

Patricia: "I walk as slowly as a snail with two sticks and I still get caught [...] and fall. I [...] always look to the floor, always, I am attentive, what else can I do?"

\section{Practice safe falling techniques}

The participants were very aware of the risks of falls and applied many strategies to prevent them, but they still fell or feared falling. The participants described falls as being completely unexpected and themselves as being unprepared. All the participants agreed that falls are not preventable and thus, safe falling techniques should be practiced.

\footnotetext{
Clara: "The other day, I got up from my bed and fell. I thought that my foot numbed, no my foot didn't numb, [...]. I was so shocked. [...] there is no prevention for it, that your limbs fail. Unless in the future you control each step with a stick, $[\ldots]$, prevention is good, but you will not be able to prevent it, because you can't. That's why it is important to limit the consequences of falling."
}

In both groups, learning how to fall safely was the most mentioned strategy to prevent injuries and the psychological consequences of falls.

\section{Additional relevant findings}

In both focus groups, there were a few topics that repeatedly arose.

\section{Estimated capacity - challenge or curtail activity?}

The participants discussed avoiding specific activities (e.g. physical activity or sports) 
to prevent falls.

Grace: "I really like biking, I fell twice. Always on the same surface, gravel! Now, I panic, $[\ldots]$, I'd rather not bike, because I am incredibly afraid."

Participants mentioned that it is very difficult to find a middle ground between avoiding activities and challenging themselves. They understood how important it is to stay active and independent, but on the other hand, the possible consequences of falls force them to avoid specific activities.

One participant explained that knowing and accepting their capacities and not exceeding it, remains an important strategy to prevent falls. Newly diagnosed participants in particular had problems with this aspect.

\section{Psychological consequences of falls}

Participants repeatedly mentioned their injuries and the psychological and emotional effects of falls; finding falls humiliating, embarrassing and causing them to avoid social situations. They also mentioned feeling frustrated and helpless. It was emphasized that falls made them feel even more insecure and unsteady. Some participants also talked about being terrified, panicked, incredibly afraid or scared. One participant said that her zest for life, her spontaneity and safety were missing because of the risk of a fall. Falls resulting in sick leave from work were also mentioned.

\section{Role of family, partners and society}

Participants mentioned that worrying partners and family is another consequence of falls, which motivates them to work on this problem. Yet, family and friends can also cause falls, if they overestimated the capacities of their family member with MS. Especially in the second group, participants discussed pressuring themselves to be quick 
(Paul: "You want to prove to yourself that you still can!"), which raises falls risk. This pressure can also be external, if family, friends or society in general (e.g. bus drivers or employers are mentioned) pressure people with MS to be quick. Participants described many occasions where they felt rushed by others.

Clara: "Sometimes I need more time than others and my husband looks at me and I say, 'I have MS!' and he says 'Sorry, I keep forgetting it'.'

Sarah: "It is so difficult when you still work. At work, you have to be quick, it is expected, it is demanded. When you have MS, you are disadvantaged. It shouldn't be like that, but it is."

\section{Discussion}

\section{Short-term programs are preferred}

The participants expressed their preference for short programs, which supports previous findings that found that adherence seemed to reduce over time with longer-duration programs [9]. Yet, it must be considered that a high program volume is needed to achieve improvements in balance outcomes [9]. Maybe, fall prevention programs should rather be used as an initial impulse for change instead of aiming an actual change. Short-term programs could focus on the essential behavioral and psychological aspects of falling and introduce balance and strength exercise. Balance and strength exercises would require a continuity in follow-up to effect balance and falls outcomes.

\section{At rehabilitation clinic or PT, OT practice}

Rehabilitation clinics seem to be the optimal setting for fall prevention programs. Participants are already on-site and can integrate appointments easily. The program could start in a rehabilitation clinic, introduce the balance and strength program and be continued as a follow-up intervention in physiotherapy or occupational therapy 
practices, sport clubs or fitness centers because participants preferred exercising with professional guidance (see 'Potential instructors').

\section{Awareness must be raised among healthcare professionals!}

As suggested by the participants, MS clinics and the MS Society should take charge in the implementation of fall prevention programs. MS clinics and MS societies could also cooperate with statutory health insurers, so the costs of the programs are covered for the participants. The participants also recommended that adherence would be increased by introducing participation fees to support financing and eventually reimbursing the program fees of participants who took part in every meeting. As high dropout rates were a problem in previous studies [10], this reward system could have a positive effect on participation. On the other hand, adopting this scheme might detrimentally affect the participation of people with poor finances or poor health would hesitate to sign up.

The perception by participants that fall prevention is neglected by healthcare professionals is consistent with the reported limited awareness, lack of guidelines and implementation of fall prevention programs in Germany [7]. It was reported before that despite the high incidence of falls, only $50 \%$ of people with MS who fell reported speaking to a healthcare professional about their falls [15]. Thus, it seems essential to include questions about falls in medical check-up questionnaires to identify fallers early in treatment and initiate a dialogue. Even more concerning was that participants believed that healthcare professionals considered falls to be an inevitable part of MS and are normal for MS.

Future research could investigate why healthcare professionals neglect fall prevention in MS. We recommend that MS researchers, MS clinics and local MS societies work together to raise awareness among healthcare professionals about fall prevention interventions. 


\section{Healthcare professionals as instructors are preferred}

The participants stated clearly that they preferred professional guidance during the program. Thus, we recommend professionals as instructors, and laymen can be considered for follow-up interventions. In this regard, it must also be reported that the participants expect more and better consultation from physiotherapists and occupational therapists regarding mobility aids and home environment modification. In Germany, it is reported that preventive home modifications depend on the initiative of affected people and their caregivers [7]. The reasons healthcare professionals are not more proactive with fall prevention needs to be investigated in future research, because again, it is unclear why they so often neglect this topic.

\section{Practical, personal and in groups}

Both groups were very clear that the program must be practical, in-person and in groups. Participants appreciated group therapy and emphasized the value of helping, teaching and motivating each other. Peer support was reported to be a facilitator for physical activity in people with MS [16]. The participants strictly rejected the idea of online therapy because they valued professional hands-on guidance during the exercises and the effects of group therapy.

As technology develops, more and more online interventions are introduced, and also in the field of fall prevention [17]. However, it was reported before that a webbased fall prevention program was not preferred by older people [18]. Thus, we recommend a critical investigation of the acceptability of online interventions, before time-consuming and expensive online interventions are developed and offered. Online interventions do have the advantage of overcoming access issues, which may be a problem for people with MS (see next section). It is possible that our participants 
strictly rejected online interventions because they all lived in a big city with a good public transportation. Thus, it is questionable whether this finding can be generalized to people who live in rural areas. Also, the median ages of the participants in our focus groups were 50 and 52 , so it is unclear how younger people who might be more comfortable with utilizing technology would react to online interventions.

\section{Mixed groups or MS groups?}

The answer to this question differed strongly between the two groups. The first group consisting of more newly diagnosed people with MS - were for MS groups and against mixed groups. The second group - consisting of people with MS with longer disease duration - were for mixed groups. The second group emphasized that the target group must be widened to offer more programs throughout the city, which would decrease traveling time.

It could be hypothesized that newly diagnosed people with MS perceive their symptoms and disease as unique and thus prefer to be among each other. It could also be hypothesized that newly diagnosed people with MS have less problems with mobility and do not worry about access problems. As the participants were recruited by convenience sampling, the difference between the groups resulted unintentionally. This led to different answers for a few topics, which suggests that fall prevention should consider the differences of newly diagnosed people with MS and people with MS with a longer disease duration.

\section{Treat impairments associated with falls}

The participants named several impairments that caused their falls (Table 4). The participants believed that treating the impairments and improving balance and strength would reduce falls in the long-term. As current fall prevention interventions are mostly 
based on strength, endurance and balance training [9], there is a match between participants' preferences and clinicians' opinions.

Balance impairment and muscle weakness [15], spasticity and low endurance [19] have been mentioned before as falls-associated factors. It was reported previously that People with MS attributed their falls to balance and lower extremity malfunction [20], which was also confirmed by our data. The impairment "dizziness" was not mentioned in previous research. Dizziness can be attributed to vestibular dysfunction or to side-effects of medication. A research group concluded that vestibular dysfunction may not be a significant predictor of falls risk, whereas the use of prescribed medications was associated with increased fall risk [21]. We recommend investigation into the prevalence and causation of dizziness in people with MS and eventually its association with falls in people with MS.

\section{What about interventions to improve attentiveness?}

Our findings concerning falls attributions of people with MS regarding risky activities and risky environmental factors (Table 4) strongly agree with other data from surveys and interviews $[20,22]$. In this context, the participants stressed the importance of being attentive, looking ahead, planning activities and recognizing fall or trip hazards. The relevance of these strategies to prevent falls were also described in previous qualitative studies $[22,23]$. We are unsure whether interventions to improve attentiveness should be included in fall prevention programs. All our participants expressed that they are applying those strategies already and all were aware of the importance of these strategies. As our participants seemed to be confident in managing falls, we recommend - just like our colleagues [23] - future research should focus on participants who are less aware of their ability to manage falls or lack the confidence in their ability to manage falls. This would clarify whether interventions to improve attentiveness need to be 
considered in fall prevention programs.

\section{Fear of falling and falling techniques}

The participants described their fall experience with extremely negative words such as humiliating, embarrassing, frustrating, feeling helpless, making them insecure and unsteady, terrifying, panicking and scaring. Those words show that falls affect the psychology of people with MS. In particular, descriptions such as panic, being afraid and scared show that fear of falling is very relevant in people with MS [4]. We have to emphasize in this context that the aforementioned negative emotions were mentioned mostly by the non-fallers in our study. The latter referenced study included people with MS without fall histories, and these participants were also concerned about falling [4]. This study was about older people with MS and fear of falling was limited to a single item, yet, our findings show that fear of falling is also relevant in people with MS who are considered non-fallers.

The most repeated keyword in this study was "falling techniques". It was surprising that the participants wished being exposed to something they associated with panic, fear and humiliation. Yet, this view complies with the idea of exposure therapy [24]. The participants explained this wish by repeating that they already apply many strategies to prevent falls, but still fall, which would confirm the conclusion of a previous study [25]. They also emphasized that falls are not preventable in MS and thus, they must learn to fall right to prevent serious injuries and to decrease fear of falling. This is a common practice in sports such as martial arts or inline skating, and many participants referred to these sports.

There was a pilot study that looked at the effect of exposure therapy on fear of falling and activity avoidance in older people [26]. The pilot study had promising results, although the participants were not exposed to falls directly, but to feared 
activities. Thus, we recommend that intervention studies should integrate falling techniques in their programs and investigate the effect it has on fear of falling and fall injuries.

\section{Estimated capacity - challenge or curtail activity?}

Peterson et al. mentioned that knowing and especially accepting one's own limited capacity is a key competence in managing fall risk [23]. Our participants repeatedly raised this issue in both focus groups. In connection with this, there are two matters that could be explored in future research: (1) The inability to gauge one's competence leading to activity curtailment and more fall risks and (2) in particular, newly diagnosed people with MS struggling with knowing and accepting their limited capacity. There is a connection in research between fear of falling and activity curtailment [4]. However, the additional hypothesis that the not knowing or accepting of capacity is also associated with activity curtailment or higher fall risk has not yet been reported. Future research that investigates this association is needed. Addressing activity avoidance and lack of perceived ability was identified as a facilitator to participation in fall prevention programs in older people [27]. Further research in this regard, will not just add value to fall prevention research in MS, but also to physical activity research in MS.

\section{Role of family, partners and society}

The participants gave many examples where family members, friends, bus drivers, employers or co-workers pressured or rushed them, which led to exceeding capacity and increased risk of falling. We recommend that family members are included in programs and learn to know and accept their partner's capacity. Family members could also learn to look ahead and recognize trip and fall hazards. A previous survey concluded that almost one-half of their participants would not want their spouse/caregiver to attend a 
fall prevention program with them [28]. As this information is from an abstract, it is unknown in which context this question was asked and why so many participants declined this chance. But if people with MS did not want their family members to be included, a separate program for family members should be considered in future research. Raising disability awareness among bus drivers, employers and co-workers should also be considered (e.g. via informational campaigns).

\section{Study limitations}

The convenience sampling lead to a few limitations. The sample consisted mainly of women $(n=8)$. A qualitative study that collects the opinion of men would be recommended, especially because men may fall more than women [19]. A few participants had less speaking time, which is a potential limitation of a focus group. An advantage was that the moderator did not have to intervene much and thus, the bias of moderator was minimal. Also, the first author is a physiotherapist with expertise in fall prevention, and the participants were aware of this. This bias is unavoidable and could have influenced the questions of the moderator and the answers of the participants. The advantage is that the moderator was sensitive to the topic and guided the discussion with relevant questions.

The data generation and analysis had a few limitations. The transcripts were translated immediately for analysis, which could have resulted in loss of meaning and thus loss of the validity [29]. Also, the transcripts were translated by only the first author without support of a professional translator. Translations should be undertaken with the support of a professional translator to maintain trustworthiness [29]. The content was coded by only one coder. Two or more coders throughout the whole coding process are recommended [14]. The first author tried to minimize this limitation by taking long breaks between the recoding. Also, the categorization and interpretations 
phase would ideally been done by triangulation (comparing the interpretations and implications drawn by multiple researchers on the same data and data display) [14], but this was not possible within the logistics of this study.

\section{Conclusion}

People with MS prefer short-term fall prevention programs that take place in rehabilitation clinics, or physiotherapy or occupational therapy practices. The participants want the programs to be organized by MS clinics and the MS Society and expect the statutory health insurers to partially or completely finance the programs. Healthcare professionals were preferred instead of laymen as instructors and an awareness of fall prevention needs to be raised among healthcare professionals. Participants expect better consultation from physio and occupational therapists regarding mobility aid and home modification. The sample want the programs to be practical, in-person and in groups. Online interventions were strongly declined. This study concludes further that people with MS want balance and strength exercises in fall prevention programs. Interventions to improve attentiveness seemed unnecessary as all participants were confident in their ability to look ahead, plan activities and recognize trip and fall hazards. Practicing safe falling technique was the most mentioned keyword in this study, and the sample persisted in the inclusion of falling techniques in programs concerning falls. Further, family members should be involved in programs as they seem to play a role in fall prevention. Lastly, it is hypothesized that the competence of knowing and accepting capacity may be an important factor in preventing falls. Exceeding capacity seems to increase fall risk and being too worried about exceeding capacity may lead to activity curtailment, which was particularly relevant for newly diagnosed people. 


\section{Acknowledgements}

The authors would like to thank the German MS Society (DMSG) Hamburg for supporting us during the recruitment. We would also like to thank all the focus group participants who volunteered their time and, without whom, this work would not have been possible.

\section{Disclosure statement}

The authors report no conflicts of interest.

\section{References}

1. MSIF. Atlas of MS 2013: Mapping multiple sclerosis around the world. London, UK: Multiple Sclerosis International Federation;2013.

2. Gunn H, Newell P, Haas B, Marsden JF, Freeman JA. Identification of risk factors for falls in multiple sclerosis: a systematic review and meta-analysis. Phys Ther. 2013;93(4):504-513.

3. Nilsagard Y, Gunn H, Freeman J, et al. Falls in people with MS--an individual data meta-analysis from studies from Australia, Sweden, United Kingdom and the United States. Mult Scler. 2015;21(1):92-100.

4. Peterson EW, Cho CC, Finlayson ML. Fear of falling and associated activity curtailment among middle aged and older adults with multiple sclerosis. Mult Scler. 2007;13(9):1168-1175.

5. Comber L, Coote S, Finlayson M, Galvin R, Quinn G, Peterson E. An exploration of fall-related, psychosocial variables in people with multiple sclerosis who have fallen. British Journal of Occupational Therapy. 2017;80(10):587-595.

6. Mazumder R, Lambert WE, Nguyen T, Bourdette DN, Cameron MH. Fear of Falling Is Associated with Recurrent Falls in People with Multiple Sclerosis: A Longitudinal Cohort Study. International journal of MS care. 2015;17(4):164.

7. Klein D, Rapp K, Kupper M, et al. A population-based intervention for the prevention of falls and fractures in home dwelling people 65 years and older in South Germany: protocol. JMIR Res Protoc. 2014;3(1):e19.

8. Spring B. Evidence-based practice in clinical psychology: What it is, why it matters; what you need to know. Journal of Clinical Psychology. 2007;63(7):611-631. 
9. Gunn H, Markevics S, Haas B, Marsden J, Freeman J. Systematic Review: The Effectiveness of Interventions to Reduce Falls and Improve Balance in Adults With Multiple Sclerosis. Archives of Physical Medicine and Rehabilitation. 2015;96(10):1898-1912.

10. Nilsagard Y, von Koch LK, Nilsson M, Forsberg AS. Balance exercise program reduced falls in people with multiple sclerosis: a single-group, pretest-posttest trial. Archives of physical medicine and rehabilitation. 2014;95(12):2428.

11. Barbour RS, Flick U. Doing focus groups. London: SAGE; 2007.

12. Silverman RM, Patterson KL. Qualitative research methods for community development. 1 ed. New York, NY: Routledge; 2015.

13. Firth N. Effectiveness of psychologically focused group interventions for multiple sclerosis: A review of the experimental literature. Journal of Health Psychology. 2013;19(6):789-801.

14. Roller MR, Lavrakas PJ. Applied qualitative research design: a total quality framework approach. New York: The Guilford Press; 2015.

15. Matsuda PN, Shumway-Cook A, Bamer AM, Johnson SL, Amtmann D, Kraft GH. Falls in multiple sclerosis. Pm r. 2011;3(7):624-632; quiz 632.

16. Learmonth YC, Motl RW. Physical activity and exercise training in multiple sclerosis: a review and content analysis of qualitative research identifying perceived determinants and consequences. Disabil Rehabil. 2016;38(13):12271242.

17. Hong J, Kong HJ, Yoon HJ. Web-Based Telepresence Exercise Program for Community-Dwelling Elderly Women With a High Risk of Falling: Randomized Controlled Trial. JMIR Mhealth Uhealth. 2018;6(5):e132.

18. Dorresteijn TA, Rixt Zijlstra GA, Van Eijs YJ, Vlaeyen JW, Kempen GI. Older people's preferences regarding programme formats for managing concerns about falls. Age Ageing. 2012;41(4):474-481.

19. Nilsagard Y, Lundholm C, Denison E, Gunnarsson LG, Mälardalens h, Akademin för hälsa vov. Predicting accidental falls in people with multiple sclerosis - a longitudinal study. Clinical Rehabilitation. 2009;23(3):259-269.

20. Peterson EW, Ben Ari E, Asano M, Finlayson ML. Fall Attributions Among Middle-Aged and Older Adults With Multiple Sclerosis. Archives of Physical Medicine and Rehabilitation. 2013;94(5):890-895. 
21. Gunn H, Creanor S, Haas B, Marsden J, Freeman J. Risk factors for falls in multiple sclerosis: an observational study. Multiple Sclerosis Journal. 2013;19(14):1913-1922.

22. Nilsagard Y, Denison E, Gunnarsson LG, Bostrom K. Factors perceived as being related to accidental falls by persons with multiple sclerosis. Disabil Rehabil. 2009;31(16):1301-1310.

23. Peterson EW, Kielhofner G, Tham K, von Koch L. Falls Self-Efficacy among Adults with Multiple Sclerosis: A Phenomenological Study. OTJR: Occupation, Participation and Health. 2009;30(4):148-157.

24. Rothbaum BO, Schwartz AC. Exposure therapy for posttraumatic stress disorder. Am J Psychother. 2002;56(1):59-75.

25. Cameron MH, Asano M, Bourdette D, Finlayson M. People With Multiple Sclerosis Use Many Fall Prevention Strategies but Still Fall Frequently. Archives of Physical Medicine and Rehabilitation. 2013;94(8):1562-1566.

26. Wetherell JL, Johnson K, Chang D, et al. Activity, balance, learning, and exposure (ABLE): a new intervention for fear of falling. Int J Geriatr Psychiatry. 2016;31(7):791-798.

27. McInnes E, Askie L. Evidence review on older people's views and experiences of falls prevention strategies. Worldviews Evid Based Nurs. 2004;1(1):20-37.

28. Comber L, Coote S, Quinn G, Galvin R. What do People with Multiple Sclerosis Want From Falls Prevention Interventions? Preliminary Results from Ireland. Archives of Physical Medicine and Rehabilitation. 2016;97(10):e99.

29. van Nes F, Abma T, Jonsson H, Deeg D. Language differences in qualitative research: is meaning lost in translation? European journal of ageing. 2010;7(4):313-316.

Table 1. Characteristics of focus group 1.

\begin{tabular}{|l|c|c|c|c|c|}
\hline Pseudonym & Clara & Patricia & Charles & Joseph & Mary \\
\hline Sex & Female & Female & Male & Male & Female \\
\hline Age & 59 & 49 & 50 & 50 & 56 \\
\hline Occupation & $\begin{array}{c}\text { Self- } \\
\text { employed, } \\
\text { full-time }\end{array}$ & $\begin{array}{c}\text { Office } \\
\text { work, full- } \\
\text { time }\end{array}$ & $\begin{array}{c}\text { Office } \\
\text { work, } \\
\text { part-time } \\
(80 \%)\end{array}$ & $\begin{array}{c}\text { Office } \\
\text { work, } \\
\text { full-time }\end{array}$ & $\begin{array}{c}\text { Medical } \\
\text { job, full- } \\
\text { time }\end{array}$ \\
\hline
\end{tabular}




\begin{tabular}{|l|c|c|c|c|c|}
\hline Living alone? & With partner & Alone & $\begin{array}{c}\text { With } \\
\text { partner }\end{array}$ & Alone & $\begin{array}{c}\text { With } \\
\text { partner }\end{array}$ \\
\hline MS Type & PPMS & SPMS & SPMS & RRMS & PPMS \\
\hline $\begin{array}{l}\text { Year of } \\
\text { Diagnosis }\end{array}$ & 2015 & 2007 & 1993 & 2011 & 2014 \\
\hline $\begin{array}{l}\text { Falls in previous } \\
6 \text { months? }\end{array}$ & Yes & No & Yes & No & No \\
\hline Mobility aid & $\begin{array}{c}\text { Walking } \\
\text { stick for long } \\
\text { distance }\end{array}$ & $\begin{array}{c}\text { Two } \\
\text { Nordic- } \\
\text { Walking } \\
\text { sticks }\end{array}$ & $\begin{array}{c}\text { Rolling } \\
\text { walker }\end{array}$ & $\begin{array}{c}\text { No } \\
\text { mobility } \\
\text { aid }\end{array}$ & $\begin{array}{c}\text { No } \\
\text { mobility } \\
\text { aid }\end{array}$ \\
\hline $\begin{array}{l}\text { Disabled access } \\
\text { at home? }\end{array}$ & No & No & Yes & Yes & No \\
\hline $\begin{array}{l}\text { Ever participated } \\
\text { in a fall } \\
\text { prevention } \\
\text { program? }\end{array}$ & No & No & No & No & No \\
\hline
\end{tabular}

Table 2. Characteristics of focus group 2 .

\begin{tabular}{|c|c|c|c|c|c|c|}
\hline Focus group & 2 & 2 & 2 & 2 & 2 & 2 \\
\hline Pseudonym & Paul & Grace & Ruby & Sarah & Charlotte & Kate \\
\hline Sex & Male & Female & Female & Female & Female & Female \\
\hline Age & 33 & 50 & 53 & 59 & 62 & 51 \\
\hline Occupation & $\begin{array}{l}\text { Warehouse } \\
\text { worker, full- } \\
\text { time }\end{array}$ & $\begin{array}{c}\text { Office } \\
\text { work, } \\
\text { part-time } \\
(50 \%)\end{array}$ & Retired & $\begin{array}{l}\text { Office } \\
\text { work, } \\
\text { part- } \\
\text { time } \\
(50 \%)\end{array}$ & Retired & $\begin{array}{l}\text { Medical } \\
\text { Job, part- } \\
\text { time } \\
(50 \%)\end{array}$ \\
\hline Living alone? & With partner & $\begin{array}{l}\text { With } \\
\text { partner }\end{array}$ & $\begin{array}{l}\text { With } \\
\text { partner }\end{array}$ & $\begin{array}{c}\text { With } \\
\text { partner }\end{array}$ & Alone & $\begin{array}{c}\text { With } \\
\text { partner }\end{array}$ \\
\hline MS Type & SPMS & RRMS & SPMS & SPMS & SPMS & RRMS \\
\hline $\begin{array}{l}\text { Year of } \\
\text { Diagnosis }\end{array}$ & 2010 & 2001 & 1999 & 1997 & 1990 & 2001 \\
\hline $\begin{array}{l}\text { Falls in } \\
\text { previous } 6 \\
\text { months? }\end{array}$ & Yes & No & Yes & Yes & Yes & No \\
\hline Mobility aid & $\begin{array}{l}\text { Rolling } \\
\text { walker }\end{array}$ & $\begin{array}{c}\text { No } \\
\text { mobility } \\
\text { aid }\end{array}$ & $\begin{array}{l}\text { Rolling } \\
\text { walker }\end{array}$ & $\begin{array}{l}\text { Rolling } \\
\text { walker }\end{array}$ & $\begin{array}{c}\text { Scooter } \\
\text { outdoors, } \\
\text { rolling } \\
\text { walker } \\
\text { indoors }\end{array}$ & $\begin{array}{c}\text { No } \\
\text { mobility } \\
\text { aid }\end{array}$ \\
\hline $\begin{array}{l}\text { Disabled } \\
\text { access at } \\
\text { home? }\end{array}$ & Yes & No & No & No & Yes & No \\
\hline
\end{tabular}


Table 3. Comparison of focus groups.

\begin{tabular}{|c|c|c|}
\hline Focus group & 1 & 2 \\
\hline Number of Participants & 5 & 6 \\
\hline Sex & 3 Females, 2 Males & 5 Females, 1 Male \\
\hline Age (Median) & 50 & 52 \\
\hline Occupation & 4 full-time, 1 part-time & $\begin{array}{c}1 \text { full-time, } 3 \text { part-time, } 2 \\
\text { retired }\end{array}$ \\
\hline MS Type & 2 PPMS, 2 SPMS, 1 RRMS & 4 SPMS, 2 RRMS \\
\hline $\begin{array}{l}\text { Year of Diagnosis } \\
\text { (Median) }\end{array}$ & 2011 & 2000 \\
\hline $\begin{array}{l}\text { History of falls in } \\
\text { previous } 6 \text { months? }\end{array}$ & 2 Yes, 3 No & 4 Yes, 2 No \\
\hline Mobility aid & $\begin{array}{l}3 \text { with mobility aids, } 2 \text { without } \\
\text { mobility aids }\end{array}$ & $\begin{array}{l}4 \text { with mobility aids, } 2 \\
\text { without mobility aids }\end{array}$ \\
\hline
\end{tabular}

Table 4. Identified impairments, activities and environmental factors.

\begin{tabular}{|l|l|l|}
\hline \multicolumn{1}{|c|}{ Impairments } & \multicolumn{1}{c|}{ Risky activities } & \multicolumn{1}{c|}{ Risky environmental factors } \\
\hline $\begin{array}{l}\text { balance } \\
\text { impairment }\end{array}$ & tripping or stumbling & $\begin{array}{l}\text { busy, noisy, bright or dark } \\
\text { environments }\end{array}$ \\
\hline feeling dizzy & pulling or dragging leg & outdoors \\
\hline muscle weakness & $\begin{array}{l}\text { turning and changing } \\
\text { direction }\end{array}$ & unknown terrain \\
\hline spasticity & moving or walking quickly & uneven roads (e.g. cobblestones) \\
\hline parasthesia & swaying, unsteady gait & broken footpaths \\
\hline low endurance & looking up during walking & small paving slabs \\
\hline instable ankle & carrying bags during walking & elevations \\
\hline dropped foot & walking the stairs & carpets \\
\hline & biking & \\
\hline & running & \\
\hline
\end{tabular}

Figure 1. Summary of themes and findings. 
prevention program (FPP): What are the views and opinions of people with multiple sclerosis?

\section{Organization of a FPP:}

- Short-term program

- In rehabilitation clinic, practice of PT/OT

- Organized by MS clinics and the MS society

- Financed by statutory health insurers

- Healthcare professionals as instructors

- Practical, in-person and in groups (rejection of online interventions)
Other relevant findings:

- Awareness for fall prevention needs to be raised among healthcare professionals

- Consultation regarding mobility aids and home modification needs to be improved

- Others (e.g. family) seem to play a role in falls

- Knowing and accepting capacity: Exceeding capacity increases fall risk; worrying about exceeding it leads to activity curtailment

\section{Content of a FPP:}

- Balance and strength exercises

- Practicing safe falling technique (as exposure therapy) 


\section{Supplementary Material 1. Discussion schedule.}

\section{Part 1}

- What is/means fall prevention?

- What do you think of fall prevention?

- What do your physicians, physio- and occupational therapists think of fall prevention? How is the situation in Hamburg/Germany?

\section{Part 2}

- Did you ever hear of fall prevention programs? What does such a program consist of?

- If you participated in a fall prevention program, what did it consist of? What did you like? Why? What did you dislike? Why?

- If we plan to develop a fall prevention program, what should we consider? Or if you could design your perfect fall prevention program, how would it look like? Please, think of content and organizational details.

- Please also answer: Mixed groups or MS groups? 1-on-1 therapy or group therapy? Personal or online? Layman/laywoman or health care professional as an instructor? 